Filarecka Agnieszka, Jęchorek Michal. Proprioceptive Neuromuscular Facilitation method in physiotherapy in patients after mastectomy. Journal of Education, Health and Sport. 2020;10(8):570-583. eISSN 2391-8306. DOI http://dx.doi.org/10.12775/JEHS.2020.10.08.061

https://apcz.umk.pl/czasopisma/index.php/JEHS/article/view/JEHS.2020.10.08.061

https://zenodo.org/record/4057163

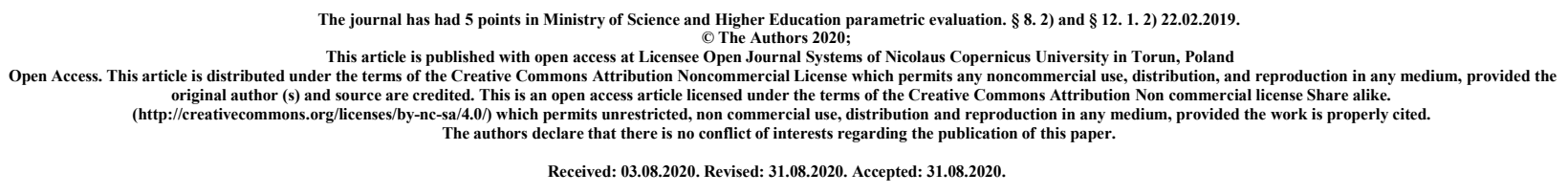

\title{
Proprioceptive Neuromuscular Facilitation method in physiotherapy in patients after mastectomy
}

\section{Agnieszka Filarecka ${ }^{1}$, Michal Jęchorek²}

Collegium Medicum, UMK Bydgoszcz, Chair and Clinic of Oncological Surgery

ToTu addiction therapy and treatment center in Karnice

Corresponding author:

mgr Agnieszka Filarecka

Collegium Medicum, UMK Bydgoszcz, hair and Clinic of Oncological Surgery

Ul. Izabeli Romanowskiej 2, 85-796 Bydgoszcz, Poland

Tel. 503074346

e-mail: aga.filarecka@gmail.com

\section{Summary:}

Rehabilitation in the course of breast cancer is an indispensable part of the treatment. The implementation of rehabilitation in the form of kinesitherapy should also take place in the pre-treatment period, so as to 
compensate for the possibility of complications associated with immobilisation of the patient after mastectomy. In most studies on post-mastectomy rehabilitation, emphasis is placed on anti-anginal prophylaxis and lymphedema therapy.

The article aims to present treatment proposals that use the concept of PNF in improved postmastectomy patients. This method, known since the 90 's, is often reserved for patients with neurological damage, but can also be successfully used in other patient groups using its main principles and philosophy of therapeutic goals. The article presents examples of activities that can be used in therapy in various phases. The paper presents the method of using the method associated with the upper limb dysfunction after mastectomy, which can be freely modified for the purposes of superior therapy. A review of available literature and own experience was used.

Key words: cancer; disability; shoulder pain

\section{Introduction}

Breast cancer is the most common malignant neoplasm in women in Poland. In recent years, the number of cases has exceeded 16,500 annually and has increased in the last two decades by about 10,000. Male breast cancer is very rare - in recent years, about 120 new cases have been registered annually [1].

In Poland, breast cancer has been the second leading cause of deaths from malignant neoplasms among women for several years (around 5,500 deaths annually) [1,2]

The etiology of most breast cancer cases is unknown. The most important risk factor is older age, followed by: carrier of mutations of certain genes (mainly BRCA1 and BRCA2), family history of breast cancer, especially at an earlier age, first menstruation at an early age, late menopause, late age of the first childbirth living baby, long-term hormone replacement therapy (HRT), exposure to ionizing radiation and certain benign breast proliferative diseases. [1.2]

Treatment of breast cancer is combination therapy. Apart from surgery, which is the first choice in the treatment of patients with this diagnosis, radiotherapy, chemotherapy, hormone therapy and other systemic treatment methods are used [1,2]

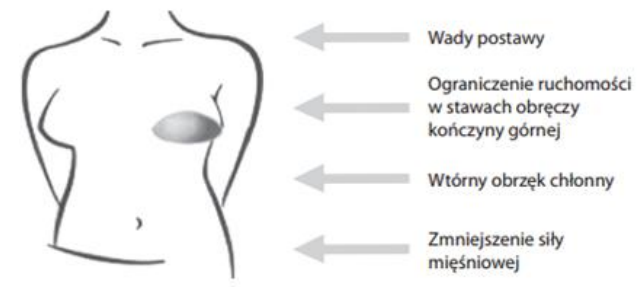

Figure 1.Side effects of breast cancer treatment [3]

The best quality of life for women should be ensured at every stage of treatment. Hence, rehabilitation in breast cancer is an extremely important element. The process of improving women after breast cancer treatment was initiated in the 1970s. Due to the damage resulting from surgical intervention, women after such surgery may have decreased self-esteem. Additionally, deformation of the body affects other structures in the body. Both of these factors adversely affect the healing process. Reduced self-esteem, mobility limitations related to surgery have a negative impact on the recovery process. Any form of rehabilitation, be it social or physical, is essential at all stages [2,3].

Due to the surgery, we can distinguish undesirable effects (Figure 1): 
- Change posture

- Limitation of mobility in the joints of the upper limb girdle,

- Secondary lymphatic edema,

- Reduction of the muscular strength of the operated side.

Physiotherapeutic treatments should be adjusted to comprehensively address all adverse effects.

In the exercise programs available to patients, the primary focus is on the problem of secondary lymphoedema. Self-draining instruction is followed [2,3]. The limitation of mobility in the joints of the upper limb, the reduction of muscle strength and the changeable body posture are forgotten.

Rehabilitation after mastectomy should take place as early as possible to prevent muscle atrophy in the area of the operated limb, which may also contribute to reduced lymph passage [3,4].

Due to a fresh scar, exercises that directly involve the structures of the shoulder girdle of the operated side are inadvisable. Using the PNF (proprioceptive neuromuscular facilitation) method, we can indirectly affect the structures located in the operated area without the fear of causing pain in the postoperative scar or its dehiscence.

\section{Literature review}

The available literature does not present the use of the method in rehabilitation therapy after mastectomy as a comprehensive therapy. The use of the method is mentioned in the case of damage to the brachial plexus or the long thoracic nerve. The paper presents a proposal to use the method in patients without damage

\section{Application of the PNF method in women after mastectomy}

Due to the surgical treatment and tissue traumatization, the therapy, through the application of the main principles - selection of the appropriate technique and irradiation, and the philosophy - painless exercise can be used in the first days after the surgery, if there are no contraindications to kinesiotherapy.

The PNF method is adopted in Poland as a treatment method in neurological patients, but its effectiveness is also noted in other groups of patients.

\subsection{Surgical treatment of breast cancer}

The basic operations performed today for breast cancer include [1]:

- excision of the tumor / lesion (wide local excision, segmental excision, quadrantectomy),

- mastectomy (mastectomy),

- sentinel node biopsy,

excision of the lymphatic system of the armpit (axillary lymphadenectomy).

In the United States and Western Europe, approximately $1 / 3$ (approximately $2 / 3$ in Poland) patients with breast cancer do not qualify for sparing treatment [1]. These women should undergo radical modified mastectomy (Madden surgery). It consists in removing the gland with most of the covering skin and the nipple, leaving the pectoral muscles larger and smaller. In the rare cases of infiltration of the pectoral muscles, it is necessary to remove them together with the breast gland (Halsted surgery). A radical mastectomy is accompanied by the removal of the contents of the armpit lymphatic system (in one block with the mammary gland). A variation of radical modified mastectomy is called Subcutaneous mastectomy, which involves the removal of all glandular tissue from the breast, including the areolanipple complex, but leaving the skin overlying the gland. In the case of this operation, the precise separation of the glandular tissue from the subcutaneous tissue and the skin is extremely important from the point of view of the risk of recurrence [1,2]. In some cases of ductal carcinoma in situ, a simple mastectomy is performed, which involves the removal of the breast without the axillary lymphatic system. This operation can also be performed as a palliative procedure due to bleeding from advanced breast cancer in a patient who is not eligible for radical surgery [1,2]. An incision is made in the breast during 
surgery. The appearance of the scar and its location depends on the technique used. In both cases, the functioning of the muscle bands is disrupted. Muscle slip disorders caused by postoperative scarring manifest themselves reduced mobility within structures. The aforementioned mobility is essential in the process of regaining the full range of mobility, muscle strength and coordination of movement $[1,2]$.

\subsection{Rehabilitation after mastectomy}

The available methods and systems of rehabilitation of people after breast cancer treatment focus in the first stages on the prevention of edema. Developed by Dr. Krystyna Mika and introduced first at the Oncology Center in Warsaw, and gradually throughout the country, in all facilities performing radical breast cancer surgery, the principles of rehabilitation apply to 3 periods $[2,13]$.

The first one is for the duration of the woman's stay in the hospital and usually lasts 3-5 days, the second after leaving the hospital, the patient should then receive assistance in a rehabilitation center or outpatient clinic, and the third - later, consolidating the obtained results: in rehabilitation centers, on rehabilitation camps in health resorts or as part of clubs for women after mastectomy (the so-called Amazons) [13, 14]. One of the most common long-term postoperative complications, affecting almost $30-50 \%$ of operated women, is lymphedema of the operated side limb. The mechanism of the edema formation is complex and not fully explained by physiologists. The most frequently mentioned causes include: disturbances in the absorption of proteins and metabolic products, mechanical obstruction of lymph flow, significant lymphatic vasodilation and valve insufficiency as well as haemodynamic lymph flow insufficiency $[2,3,13]$.

An important cause of lymphoedema that develops immediately after the operation, which then becomes permanent, is the reduction in the motor activity of the operated side limb. Pain felt when performing a movement inhibits its performance, which affects the flow of venous blood and lymph. Hence, the overriding principle of the PNF method, which says that there is no pain during exercise, proves that it can be used in the treatment of women after mastectomy.

During the procedure, damage to the long thoracic nerve may occur, which will manifest itself in the appearance of a protruding scapula $[1-3,13]$.

Disorders of the sliding of the scapula on the back wall of the chest may cause pain in the shoulder area during arm movement [10].

According to building motor control, the first pillar is mobility [10]. The preparation of a scar in order to restore the muscle slip is an indispensable element of rehabilitation. Obtaining the stability of the blade is the next step. Mobility on stability in this case will mean the ability to move the other limbs using the limb on the operated side as a support point. Dexterity is related to the performance of activities with the limb directly affected in this case on the operated side.

\subsection{Therapy acc. PNF concept}

In the course of therapy, its goal should be established first. For this purpose, we can use the ICF classification.

This classification requires objective tests to be performed at both the structural and activity levels. In a structural context, measurement tests and tests, e.g. of the range of motion of the SFTR, are performed. The purpose of the tests is to hypothesize the cause of the problem with daily activities (ADL). At the level of daily activity, repeatable measurable tests are performed $[11,12]$. 


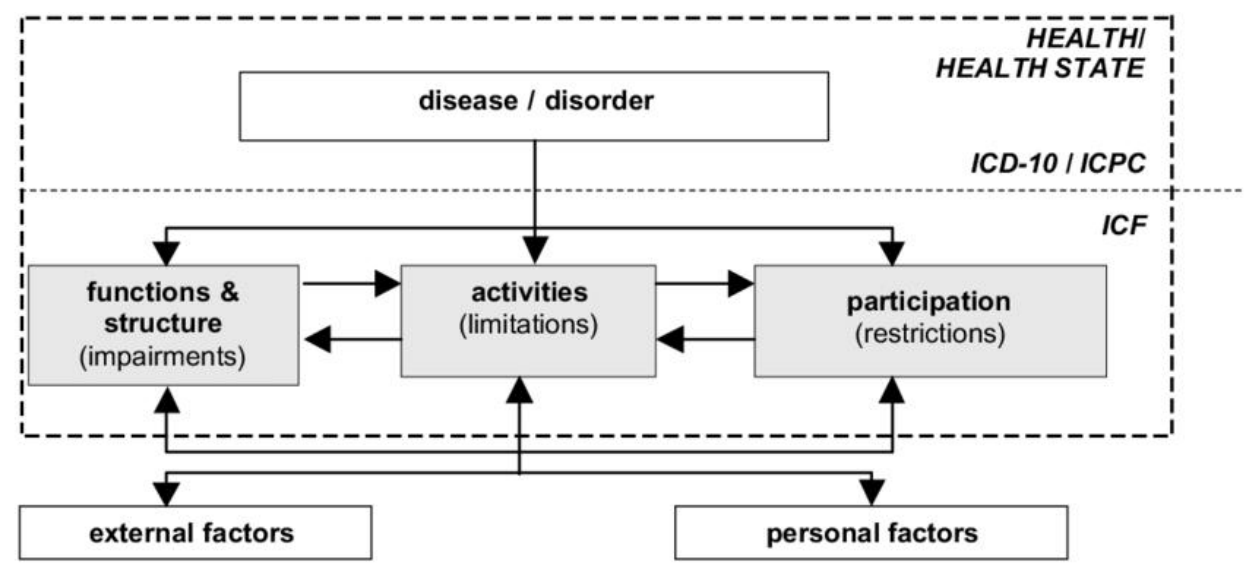

Figure 2. The scheme of determining the therapy according to ICF [12]

For women who have undergone a mastectomy, the ICF classification may be as follows:

At the structure level:

- There is no slip between the pectoral muscle and the surgical incision scar

At activity level:

- Limitation of upper limb flexion, abduction and external rotation

At the level of participation:

- Inability to reach the glass from the cupboard

Depending on the therapeutic program, the therapy can be started "bottom-up" or "top-down", starting either from the level of structures or participation. In both procedures, it is important to achieve the goal set by the patient - reaching a glass.

The most common method is "from top to bottom", which means that we know the purpose of the therapy - in this case, reaching the glass. Our task as therapists is to find the problem in terms of activity and structure. By working on the structure, we start the therapy in a "bottom-up" scheme, that is, we go through the structure, activity to the level of participation.

\subsubsection{Proprietary therapy}

In the first stage after the procedure, it is recommended to use techniques in which there is no movement but isometric muscle tension. Working on distant structures and transferring the tension from the pelvis, the second upper limb, the scapula of the lower limbs to the shoulder girdle, can also be used effectively in the first stage of therapy.

At a later stage, while working on the stability of the scapula, we can use supports on the forearm of the operated limb. We can use the support while sitting down, lying on the side or lying on the back or stomach. The variety of the method makes it possible to change the stimuli and constantly stimulate the nervous system. 
During therapy, we can work in the following way [10]:

- Starting with a stronger pattern,

- By replacing synergy for distal elements,

- Distal and proximal facilitation should be about the same synergy,

- We use resistance

- Movement changes should be preceded by verbal commands.

Objective: Eccentric work of the pectoral muscle and mobilization of the shoulder plexus [5-8,10]

Exercise: Rolling the patient from lying on his side to lying on his back, rotation of the lower body while lying on his back.

It is recommended to perform a slow rotation for supine position or a rotation of the lower body.

We can use the following patterns for facilitation:

Head Pattern: Neck bend with a side inclination towards the patient's rotation. Rotating the head and looking towards the lower limb (Figure 3)

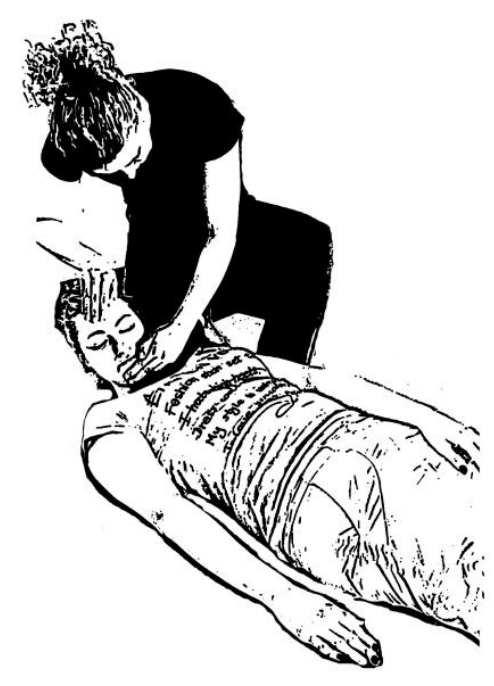

Figure 3.The head flexion pattern during the mobilization of the shoulder plexus and facilitating the eccentric work of the greater pectoral muscle on the right side.

Upper limb pattern:

Through patterns on the unoperated upper limb, the patient is instructed to return to the starting position (pattern of flexion / abduction / external rotation with extension in the elbow joint) or a radial pull pattern and an elbow pull pattern

Lower limb pattern:

Higher positioned lower limb moves in eccentric work from flexion / adduction / external rotation towards extension / abduction / internal rotation. 
In the supine position, it is also possible to activate two limbs in flexion synergy with simultaneous stabilization of the mobilized upper limb (Figure 4).

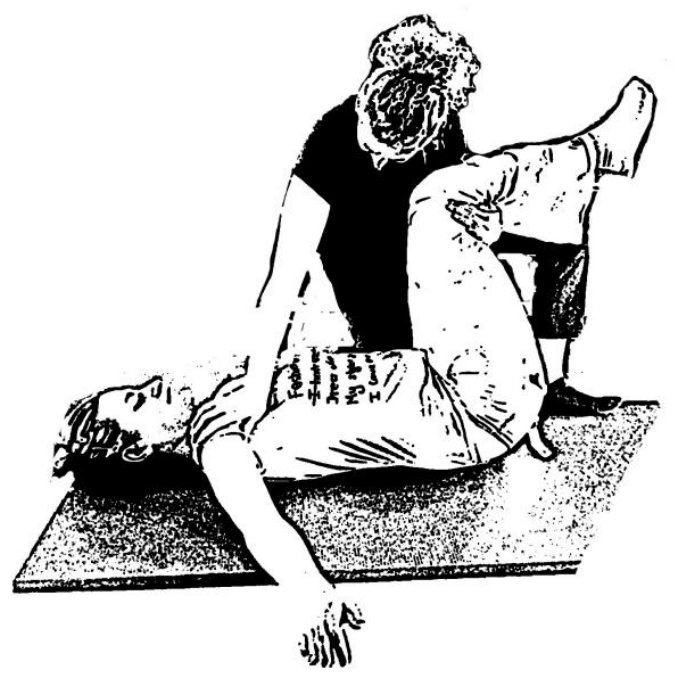

Figure 4. The use of lower limb flexion synergy with a stabilized shoulder to mobilize the greater pectoral muscle on the right side

In order to achieve mobility, we can use closed chains, which will additionally stabilize the starting position. The recommended technique that affects mobility is relaxation techniques.

\section{Objective: Mobility [5-8,10]}

Initial position:

Sit with your forearms propped, sit down with your hands propped, kneel with a prop on your forearms, and a deep knee propped (Figure 5).

Exercise: "Rocking", sit on your heels

The patient is instructed to perform pelvic fore and aft tilt (Figure 6). By working on the pelvis, we obtain the extension of the pectoral muscles of the greater, smaller, two-headed shoulder, dentate muscles, round muscles, broadest back, over and subcapsular, under-scapular, triceps and other upper limbs. Depending on the application of the technique, we work in concentric or eccentric contractions of the abovementioned muscles.

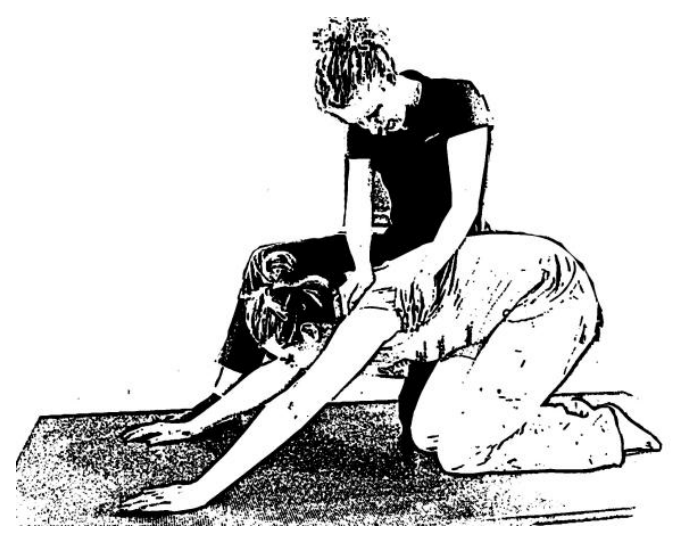

Figure 5. Working on the mobility of the pectoral muscle and the widest spine in an eccentric contraction, the therapist's right hand facilitates external rotation. 


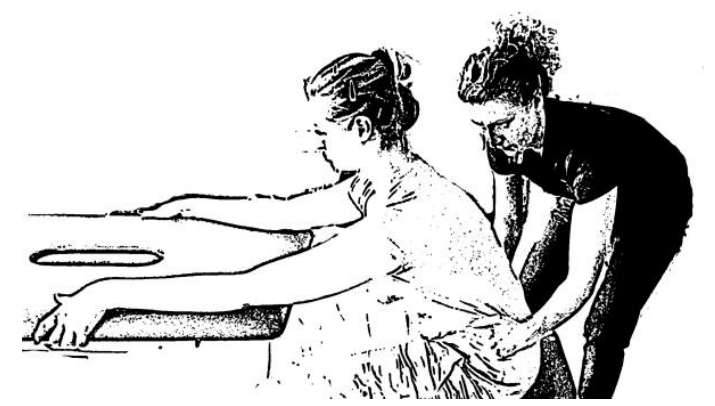

Figure 6. "Rocking" in a sitting position in a closed chain. Facilitation of the eccentric and concentric work of the pectoral muscle and the latissimus by working on the pelvis.

In exercises that improve the stability of the scapula, it should be noted whether the ascending part of the trapezius is stimulated. Active lower torso flexors with proper support activity. If the spine extensors are triggered during the exercise, the patient may be pulling the retraction shovel. This is the case when the arm is too much dorsal or medial. If the patient does not have the appropriate stability of the scapula, it can be improved by working in closed chains (Figure 7). I propose a therapy from closed to open chains.

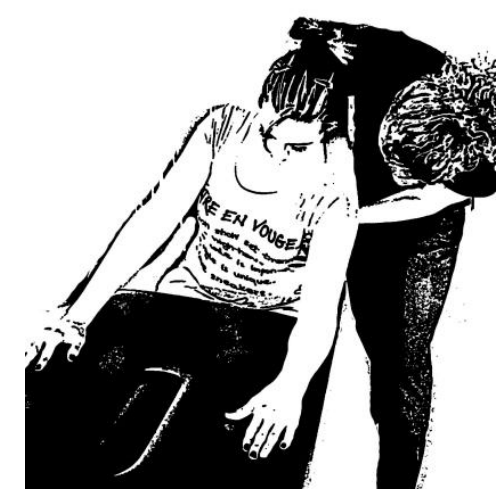

Figure 7. Closed chain support on the forearm of the left hand. Shoulder approximation to enhance the facilitation of the scapula stabilization. The patient's other limb - extension in the elbow in order to transfer the weight to the right limb

Objective: Use of shoulder mobility, improving dynamic stability [5-8,10]

Starting position: standing in front of the ladder

Exercise: Climbing the ladder.

The patient is advised to climb the ladder (figure 8). He reaches up with his dysfunctional hand and raises the opposite leg to the step. In this way, we obtain an elongation of the trunk on the shortened side. When pulling up, the elongated side is shortened. 


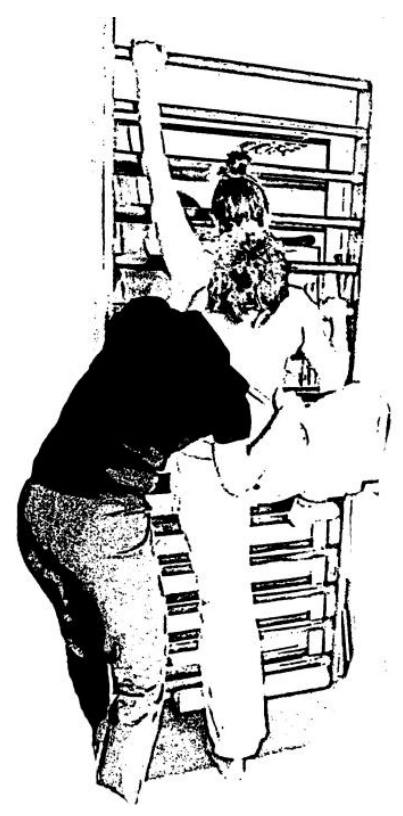

Figure 8. Amphibious position when climbing ladders. The patient's left limb is positioned in external rotation. The therapist's right hand facilitates the front elevation of the pelvis on the right side, influencing the extension of the patient's left side

Objective: To develop the correct timing of the scapula during the forward and upward movement of the upper limb with unloading [5-8,10].

Starting position: lying on your side

Exercise: Elbow pushing pattern and front elevation of the scapula (Figure 9).

The patient is advised to deliberately move the upper limb forward and up, eg. An object is placed on the corner of the rehabilitation table and recommended to reach it. First, we facilitate depression by maintaining the upper angle of the scapula, then the rotation of the scapula is facilitated - the lower angle to the side.

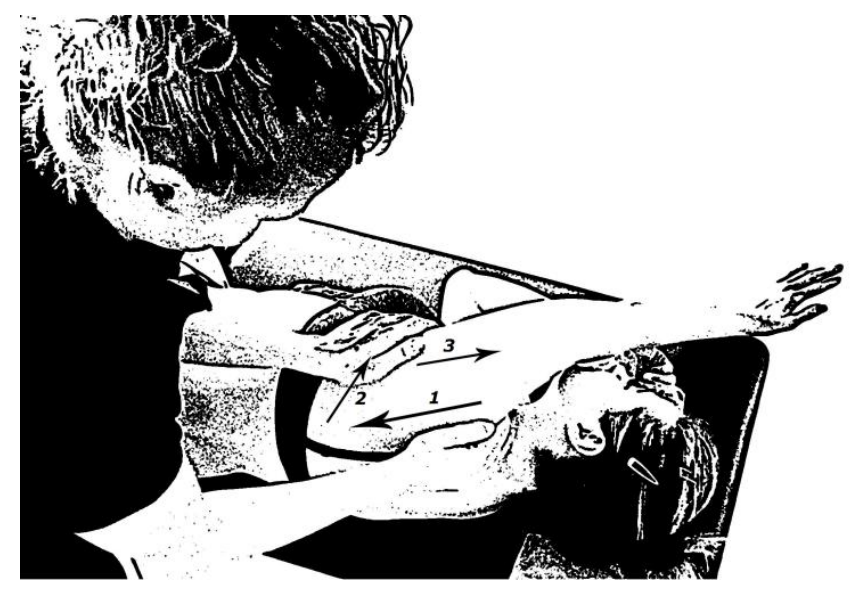

Figure 9. Elbow bulldozing pattern and front elevation of the blade, paving the correct timing of the blade in numerical order. 


\section{Arm instability}

Instability manifests itself in support activities and during catching, as these activities require cocontracting. With the ejection movement, it is necessary to accelerate, which is associated with reciprocating innervation, the instability of the arm will be manifested by a reduction in the ability to perform the movement. The stability of the shoulder and trunk is essential for the motor skills of the small hand [10].

During the therapy of shoulder instability, the therapy strategy can be changed [10].

- It is recommended to work on a weaker pattern, because we want to recruit as many motoneurons as possible.

- The change of grips occurs proximally at first, which increases the feedforward and activates the muscle work that is necessary in the proximal segment.

- The proximal and distal sections should be facilitated in opposing synergies that lead to greater stability.

- The resistance to the distal component is neglected as stability is guaranteed by subcortical reflex pathways and these require prioprioceptive information. Applying resistance distally could dislocate the shoulder joint due to the use of a long lever.

Objective: Slide the shoulder blade over the chest, activation of the muscles stabilizing the shoulder blade Starting position: sit down with your forearm supported.

Exercise: Rotating the upper torso, extending the arm at the elbow

The patient is recommended to rotate the upper torso in order to mobilize the posterior and trapezius muscles of the middle and ascending parts of the parallelogram muscle. The therapist facilitates the posterior depression scapula (Figure 10).

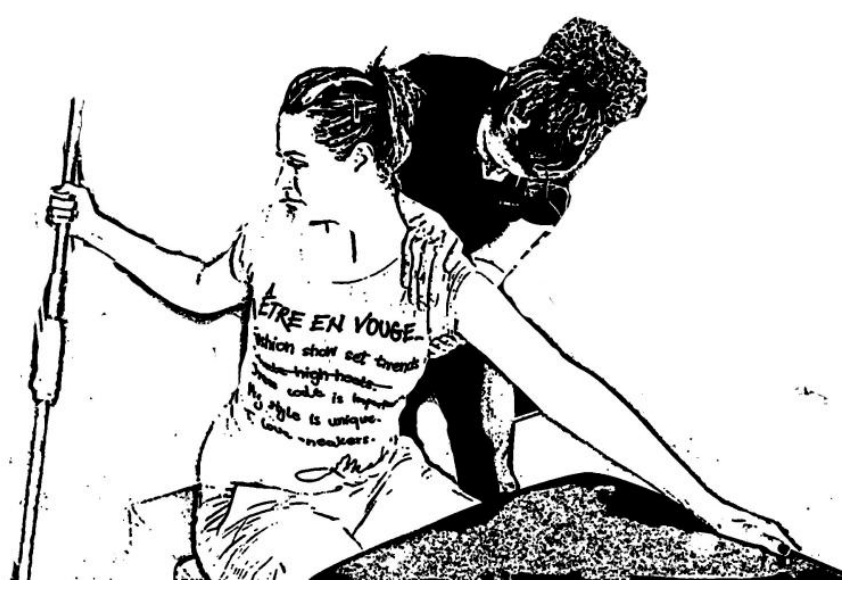

Figure 10. Rotation of the upper torso, activation of the sliding of the scapula on the posterior wall of the thorax, stabilization of the scapula in posterior depression.

Objective: Braking activity of external rotators during movements that require slowing down $[5-8,10]$ Exercise: Elbow Pushing Pattern

The patient is recommended to push the arm forward and brake in front of the wall, or use the amphibious position while lying on a mattress or standing against the wall, climbing ladders or a climbing wall. The 
dysfunctional arm reaches upwards and the ipsilateral lower limb is the support leg, the contralethal is the front leg. Pulling up causes caudalization of the humeral head (Figure 8).

Objective: Increasing postural control through arm support activities [5-8,10]

Starting position: on your knees, standing with your hands supported

Exercise: Jumping (Figure 11)

The patient is recommended to jump, the therapist facilitates the grasp of the pelvis, so that the weight of the body is transferred to the hands. It is important to stabilize the patient's shoulder depending on the position selected.

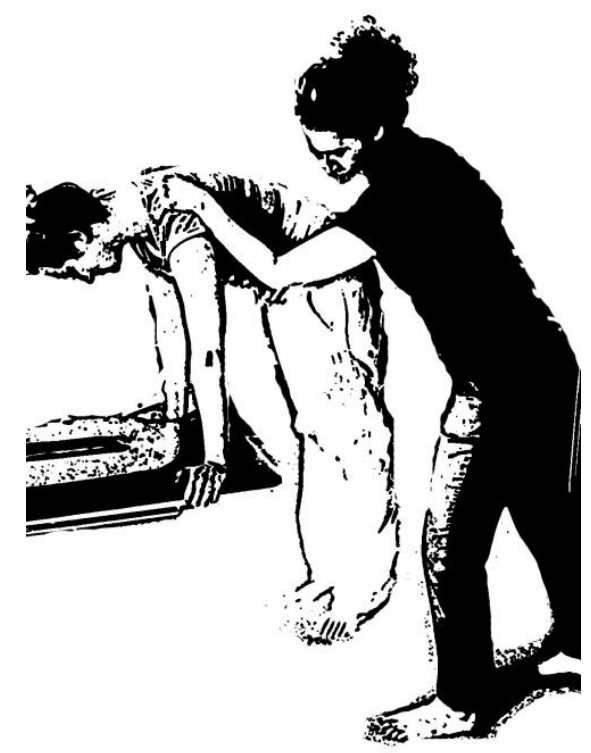

Figure 11. Activation of the support in dynamic work in bounces. Weight transfer to the upper limbs. The therapist, through approximation, facilitates the stabilization of the support. With the other hand, he performs a pelvic stretch to posterior depression as an impulse to jump.

Exercise: stretching the other hand forward [5-8,10]

The patient is advised to reach forward with the other hand, such as wiping the floor or touching the wall, so that the weight of the body is transferred to the shoulder on the opposite side.

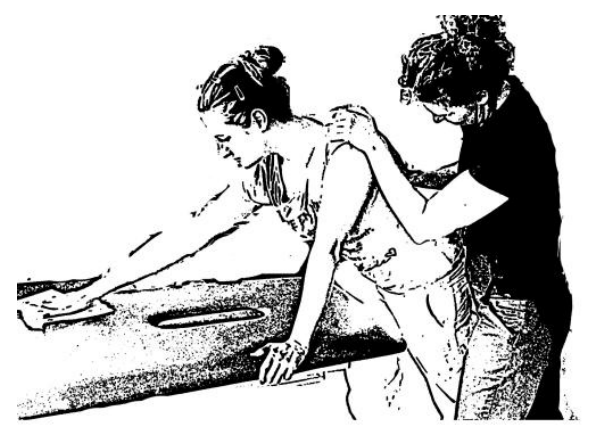

Figure 12. Activation of a support in a closed chain. Weight transfer to the left upper limb. The therapist, through approximation, facilitates the stabilization of the support. The other hand facilitates the depression of the posterior scapula 
Objective: Support activity in the squat in order to activate the anterior dentate and latissimus dorsi muscle $[5-8,10]$.

Starting position: sit straight, sit on the chair

Exercise: Raising the hip - scooting - or hips up using the hands.

The patient lifts one side of the pelvis, activating the latissimus dorsi muscle and the toothed anterior muscle, and at the same time the posterior scapula on the side of the elevated pelvis is depressed (Figure 13).



Figure 13. Activation of a support in a closed chain. Weight transfer to the right upper limb. The therapist, through approximation, facilitates the stabilization of the support. The other hand facilitates the pelvis for anterior and posterior elevation alternately.

Objective: Facilitation of stability in rotation external during activity [5-8,10]

Starting position: sit down

Exercise: extension / abduction / external rotation with bent elbow

The patient is advised to catch the ball. Catching the ball generates a stretching stimulus for the external rotators. The therapist facilitates the external rotators by rotating the arm outward to approximate the external rotator cuff attachments (Figure 14).

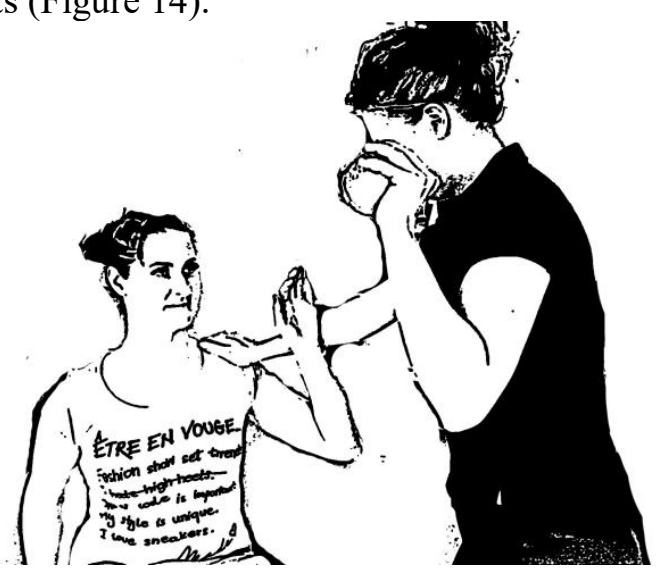

Figure 14. Tracking stability in external rotation in dynamics. The patient catches the ball, the therapist facilitates the external rotators of the arm. 
Exercise: extension / abduction / internal rotation to extend the elbow [5-8,10]

The patient is advised to throw the ball. The ejection of the ball generates the eccentric work of the external rotators, which are designed to slow down the acceleration of the arm, acting synergistically with the internal rotators. The therapist facilitates the external rotators by rotating the arm outward to approximate the external rotator cuff attachments (Figure 15).

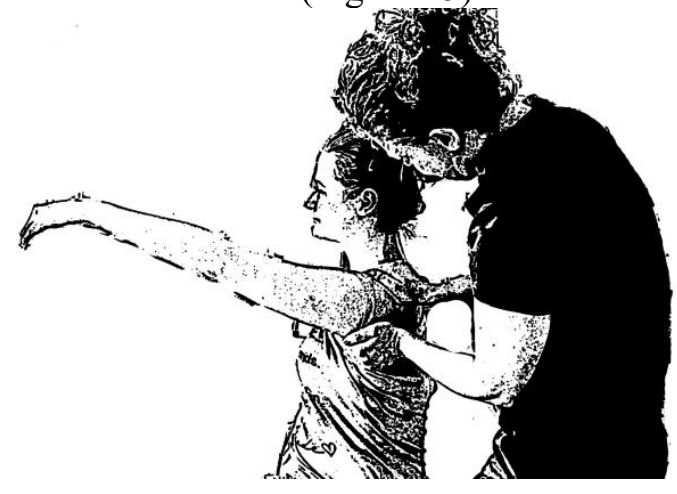

Figure 15. Tracking stability in external rotation in dynamics on the example of ball throw. The therapist facilitates

\section{Conclusions} external rotators for eccentric work.

The PNF rehabilitation method can be successfully used in women after mastectomy, both with and without damage to the brachial plexus.

The presented exercises are a proposal for post-mastectomy therapy. Depending on the patient's abilities, they should be adjusted to the needs of the therapy. In the first step, the focus should be on achieving mobility and stability. The techniques used in stability therapy should be appropriate to the goal. The main rule should also be used - timing for emphasis - working only on a fragment of the pattern to strengthen and emphasize the movement.

During therapy, commands are an important element, which should be understandable short and unambiguous. Before starting therapy, its purpose should be defined. Testing should be performed to monitor the progress of therapy.

\section{Literature}

1. Jassem J. Krzakowsk M. (red) Rak piersi. [W]: Krzakowski M. Warzocha K. (red.) Zalecenia postępowania diagnostyczno-terapeutycznego w nowotworach złośliwych 2013 . Via Medica, Gdańsk 2013; 213, 230-236

2. Hawro R. Matkowski R. Rehabilitacja po leczeniu raka piersi. [W]: Woźniewski M. Kornafel J. (red.). Rehabilitacja w onkologii. Elsevier Urban \& Partner, Wrocław 2010; 181-197

3. Tchórzewska H., Rehabilitacja w leczeniu raka piersi. [W] Pawlicki M. (red.). Rak piersi - nowe nadzieje i możiwości leczenia. Wyd. 2. Alfa Medica-Press, Bielsko-Biała 2011; 99-120.

4. Tchórzewska H, Fizjoterapia w leczeniu chorych na raka. [W]: Szukiewicz D. Fizjoterapia w ginekologii i położnictwie, Wydawnictwo Lekarskie PZWL, Warszawa 2012, 160-172

5. Adler S.S., Beckers D., Buck M.: PNF w Praktyce. Ilustrowany przewodnik. Wydanie III, Warszawa 2009 
6. Kabat H., Knott M.: Proprioceptive facilitation techniques for treatment of paralysis. Phys. Ther. Rev., 1953, 33, 2, 53-64

7. Górna E. Proprioceptive neuromuscular facilitation, Skrypt kursu podstawowego PNF, Bydgoszcz 2014.

8. Górna E. Proprioceptive neuromuscular facilitation, Skrypt kursu rozwijającego PNF, Warszawa 2016.

9. Zagłoba-Kaszuba A., Huber J., Stryła W. i wsp.: Analiza elektromiograficzna czynności mięśni kończyn dolnych w trakcie wykonywania wzorców PNF. [W]: Huber J., Wytrążek M., Kabsch A. (red.), Kierunki rozwoju neurofizjologii klinicznej i fizjoterapii i terapii manualnej. , Wydawnictwo Naukowe Uniwersytetu Medycznego im. Karola Marcinkowskiego w Poznaniu, 2010, 104-113

10. Horst R. Trening strategii motorycznych i PNF, Top School, Kraków 2010

11. Heerkens Y. Hendriks E. Oostendorp R., Assessment instruments and the ICF in rehabilitation and physiotherapy, Rehabilitacja Medyczna 2006, Tom 10, Nr 3, 11-20

12. Lupa A. Badania pacjenta zgodnie z wytycznymi ICF. Praktyczna Fizjoterapia i Rehabilitacja 2010; 5: 27-33

13. Mika K. Po odjęciu piersi. Wydawnictwo Lekarskie PZWL, Warszawa 2005

14. Terlikowski R., Balewska M. Aktywność fizyczna i dieta w terapii raka piersi. [W]: KrajewskaKułak E. (red.). Problemy terapeutyczno-pielęgnacyjne od poczęcia do starości. Białystok 2007; 423426. 